$p$-ISSN 1693-9484, $e$-ISSN : 2621-8313

Majalah Ilmiah Bahari Jogja (MIBJ)

Vol. 18 No. 2, Juli $2020 \quad$ (26-33)

DOI : $10.33489 /$ mibj.v18i2.243

C2020 Sekolah Tinggi Maritim Yogyakarta

\title{
Pengaruh Validity dan Reliability Terhadap Kualitas Delivery PT. Hanoman Sakti Pratama
}

\author{
Fatrodin $^{*}$ \\ ${ }^{1}$ Sekolah Tinggi Maritim Yogyakarta, Jl. Magelang KM 4.4, Yogyakarta 55284, \\ Indonesia \\ * Corresponding Author. E-mail : fatrodinnursehastimaryo@gmail.com, \\ Telp : 08127001037
}

\begin{abstract}
Abstrak
Persaingan ketat menyebabkan layanan freight forwarding sangat dibutuhkan dalam bisnis ini. Tujuan penelitian adalah untuk mengukur kualitas pengiriman PT. Hanoman Sakti Pratama meneruskan berdasarkan persepsi kepuasan pelanggan. Hasil: (1) Kualitas validitas-reliabilitas-pengiriman menunjukkan bahwa aliran garis arus, koefisien korelasi validitas terhadap reliabilitas lebih kecil daripada validitas kualitas pengiriman; (2) Keandalan pengiriman dipengaruhi oleh barang ketika dikirim tepat waktu, tidak ada biaya tambahan, dan tidak menyebabkan klaim karena barang yang rusak selama menangani pengiriman; (3) Kualitas pengiriman efektif pada konsumen dipengaruhi oleh keandalan pengiriman dengan penanganan yang ramah, dan layanan setelah pengiriman.
\end{abstract}

Kata Kunci: Kualitas Pengiriman, Freight forwarder

\begin{abstract}
Fierce competition lead to bush freight forwarding services are needed in the business. Study aim is to measure the quality of delivery of PT. Hanoman Sakti Pratama forwarding on customer's perception satisfaction-based. The results: (1) Validity-reliability-delivery quality shows that the stream line flow, the correlation coefficient of validity to reliability is smaller than the validity of delivery quality; (2) Delivery reliability is affected by goods when delivered on time, no additional costs, and does not cause claims due to damaged goods during handling delivery; (3) Delivery quality effectively on consumers is influenced by reliability of delivery with friendly handling, and after delivery service.
\end{abstract}

Keywords: Freight forwarder, delivery quality

\section{PENDAHULUAN}

Layanan prima telah menjadi tuntutan yangwajib dipenuhi setip organisasi bisnis agar mampu bersaing secara efektif dalam pasar yang semakin kompetitif dewasa ini. Kini terjadi pergeseran paradigma, dari yang semula goog-domiant logic menjadi servive-dominant logic (Tjiptono, 2012). Esensinya, penyediaan 
layanan merupakan tujuan fundamental dari transaksi ekonomi, baik yang dilakuka individual maupun organisasi bisnis.

Organisasi bisnis niscaya memerlukan transaksi ekonomi dalam memasarkan produknya. Perusahaan yang profesional melaksanakan fungsifungsi utama bisnis secara khusus oleh depatemen tertentu yang spesifik pula (Piercy and Cravens, 2013). Salah satu fungsi pemasaran yang sangat penting adalah penghantaran (delivery) produk. Organisasi bisnis yang produknya berupa jasa, pelayanan delivery jasanya merupakan aktivisa krusial. Oleh karenanya harus ditangani dengan sangat hati-hati dan terukur.

Bisnis maritim merupakan bisnis jasa, fungsi delivery yang merupakan kegiatan akhir dari bongkar-muat (Suyono, 2007) dilaksanakan oleh perusahaan bongkar-muat (Undang-Undang Nomor 17 Tahun 2008). Pada rentang kegiatan yang lebih luas fungsi delivery dapat dikerjakan oleh perusahaan freight forwarding (FF). Jasa FF semakin dibutuhkan dalam bsnis yang profesional, terlebih dalam bisnis maritim (Wood, Barone, Wardlow, 2002). PT. Hanoman Sakti Pratama adalah perusahaan FF yang beroperasi di lingkungan pelabuhan Tanjung Perak Surabaya, salah satu layanan yang ditawarkan adalah jasa delivery. Menghadapi semakin kompetitif dari perusahaan sejenis, kinerja delivery harus semakin terukur dengan baik. Parameter pengukuran kualitas jasa yang lazim digunakan menggunakan gagasan Berry and Parasuraman (1991), yaitu reliability, tangibility, responsiveness, assurance dan emphaty.

Penelitian tentang layanan pada industri maritim masih terbatas. Tujuan penelitian ini mengukur kualitas delivery PT. Hanoman Sakti Pratama yang merupakan salah satu jenis industri maritim, berdasarkan persepsi kepuasan pelanggannya. Jika kinerja perusahaan perusahaan tercapai maka dalam jangka panjang perusahaan akan tetap mampu bertahan dan berkembang karena kepuasan pelanggan merupakan tujuan utama pemasaran perusahaan (Piercy and Cravens, 2013).

\section{KAJIAN LITERATUR}

\section{Kualitas Produk}

Literatur pemasaran semua menyebutkan bagaimana pemasaran sukses. Praktis semua mempersyaratkan pelayanan prima kepada pelanggan. Dalam pemasaran produk berupa jasa (pelayanan), pelayanan prima adalah berupa kualitas jasa tersebut. Perspektif ini memandang nilai (value) dan harga jasa tersebut. Dengan mempertimbangkan trafe-off antara kinerja dan harga, kualitas didefinisikan sebagai affordable excellence, yaitu tingkat kinerja terbaik atau sepadan dengan harga yang dibayarkan. Kualitas di sini bersifat relatif, sehingga suatu produk yang mempunyai kulitas paling tinggi belum tentu produk paling bernilai. Produk paling bernilai adalah produk yang paling tepat dibeli (best-buy) (Tjiptono, 2012). Untuk menjadi best-buy tentu didasarkan pada persepsi pelanggan.

Para ekonom klasik menyoroti nilai sebagi manfaat penggunaan terhadap suatu barang, sesuatu yang dapat memuaskan permintaan. Nilai diciptakan dengan pengorbanan biaya, oleh karenanya bernilai jual, dan nilai bersifat subyektif bagi 
setiap konsumennya (Brewer, 2008). Walupun perusahaan menawarkan produk atau jasa yang berbeda dari perusahaan lain, produk atau jasa akan bernilai kalau konsumen merasa dipuaskan (Lee, Nam, and Song, 2015). Menurut Christopher, 2011), nilai adalah rasio antara fungsi teknis produk jasa yang ditawarkan kali komitmen mutu yang dijanjikan penjual dibagai biaya yang dikeluarkan konsumen kali waktu. Rumusnya sebagai berikut.

Fungsi teknis produk x Komitmen mutu penjual

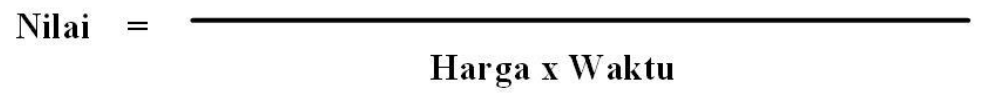

Maka nilai di sini orientasinya adalah kepuasan konsumen atas produk atau jasa yang dibelinya. Untuk memenuhi kepuasan konsumen, diperlukan variabelvariabel pembentuknnya, yaitu vailidity dan reliability.

\section{Delivery}

Delivery atau penghantaran adalah bagaimana suatu jasa sampai ke tangan konsumen secara efektif. Menurut Piercy and Cravens (2013), fungsi pemasaran yang sangat penting adalah penghantaran delivery. Dalam operasi pelabuhan, khususnya operasi bongkar-muat kegiatan stevedoring, cargodoring, dan delivery adalah kegiatan utama perusahaan bongkar-muat (Suyono (2007). Maka delivery menjadi kegiatan yang paling mudah dibuktikan oleh konsumen apakah kegiatan tersebut efektif atau tidak, kartena merupakan kegiatan terakhir dari bongkarmuat.

Kegiatan penghantaran ini dapat dilaksanakan di sisi kapal langsung ke truk (truck lossing) atau ke tongkang, dan di sisi gudang/container yard bagi barang melalui gudang/ container yard, selanjutnya diserahkan sesuai term penghantaran yang disepakati oleh pemilik barang dengan FF. (Lasse, 2014). Menurut Suranto (2004), delivery adalah pekerjaan memindahkan barang dari penumpukan di gudang/ container yard dan menyerahkannya sampai tersesun di atas kendaraan di pintu gudang/ container yard atau sebaliknya.

Kegiatan delivery umumnya menggunakan jasa FF. Hal ini karena FF mempunyai profesionalitas dalam kegiatan tersebut dan kegiatan logistik lainnya (Bernal, Burr, and Johnsen, 2002), sehingga akan lebih efektif dan efisien. Maka pergerakan barang melalui pelabuhan agar lebih efektif dan efisien dilaksakan oleh perusahaan FF.

Berdasarkan berbagai pendapat di atas dapat disimpulkan bahwa yang dimaksud dengan delivery adalah serah terima / penyerahan barang oleh pengangkut (carrier) kepada penerima (consignee) atau perwakilannya (FF) dari sisi kapal langsung ke truk atau ke tongkang, atau dari sisi gudang atau lapangan penumpukan ke truk, yang merupakan rangkaian sterakhir dalam operasi dermaga (berth operation).

\section{Vailidity}

Validity dalam arti lugas adalah keabsahan atau kebenaran sutu produk. Arti spesifik yang diberikan oleh Van Raaij and Pruyn (1998) adalah:

"Is the service specified and designed to accurately reflect what the customer wants. In service markets, customers contribute to a service by providing information about the desired requirements. Did the customer 
correctly explain what he or she wanted? Did the service provider understand and correctly interpret the requirements and queries of the customer? Customers may perceive the service provider more positively if the provider listens and uses the information given by the customer"

Kata kuncinya adalah produk tersebut memenuhi keinginan konsumen, sesuai spesifikasi rancangannya (Tjiptono, 2012).

\section{Reliability}

Reliability secara lugas diartikan sebagai keandalan suatu produk. Untuk produk berupa fisik reliability dapat dilihat dari keawetan berfungsi produk tersebut (Tjiptono, 2012), atau sangat bermanfaat (high useness). Van Raaij and Pruyn (1998) memberikan deskripsi cukup lengkap sebagai pernyataannya sebagai berikut:

"Service throughputs (processes) are focused on the realization of the specified service. To address the question of quality of service realization, the term service reliability is used. High service reliability is a flawless performance of the prespecified service. The reliability question is: Is the specified service correctly provided? Service throughput involves the service encounter, human contact, operations, time, and environmental factors, such as the presence of other customers during the service performance".

Kata kuncinya adalah proses realisasi penghantaran jasa yang apakah melibatkan human contact yang baik, ketepatan penghantaran, dan apakah layanan yang dijanjikan disediakan dengan benar. Referensi yang paling banyak dirujuk tentang kulitas jasa adalah Berry and Parasuraman (1991), memberikan terminologi reliability sebagai the ability to perform the promosed service dependably and accutalelly. Maka kemampuan melakukan layanan yang dijanjikan secara andal dan benar merupakan roh dari reliabilitas suatu jasa.

\section{METODE PENELITIAN}

Metode penelitian ini menggunakan path analysis. Pengumpulan data dengan survey, sampel ditentukan secara sengaja / terpilih dari populasi yang mempunyai relevansi dengan topik. (Sugiyono, 2012). Jumlah sampel terpilih sebanyak 50 orang pelanggan (pengirim atau penerima barang), yang kembali dan dapat dianalisis sebanyak 40 sampel. Untuk memenuhi kaidah analisis kausalitas, data lebih dulu diuji dengan asumsi klasik, terdiri dari: (1) Uji Normalitas (Supranto, 2009); dan (2) Uji Linearitas (Astriawati, 2016). Setelah data diuji dengan syarat asumsi klasik kemudian diuji korelasi dari masing-masing hubungan dengan uji t atau uji parsial (Sugiono, 2012).

\section{Penentuan Model Analisis}

Model analisis jalur yang ditunjukkan pada gambar 1 sebagai berikut.

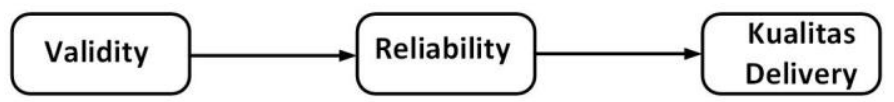

Gambar 1. Model Analisis 


\section{Penyusunan Hipotesis}

Agar analisis penelitian yang bersifat uji ini tercapai, maka dirumuskan hipotesis sebagai berikut:

1. $\mathrm{H} 0: \mathrm{V} 1 \neq 0$

$\mathrm{H} 1: \mathrm{V} 1=0$

2. $\mathrm{H} 0: \mathrm{R} 1 \neq 0$

$\mathrm{H} 1: \mathrm{R} 1=0$

Keterngan:

V1 : Pengaruh validitas $(\mathrm{X})$ terhadap reliabilitas $(\mathrm{Y})$

$\mathrm{R} 1$ : Pengaruh reliablilitas (Y) terhadap kualitas delivery $(\mathrm{Z})$

\section{Definisi Operasional}

Validity adalah bahwa jasa delivery memenuhi keinginan konsumen, sesuai spesifikasi rancangannya. Indikatornya adalah: (1) Barang dihantarkan tepat waktu; (2) Biaya tambahan di luar tarif; (3) Barang tidak rusak. Masing-masing indikator dengan derajat 1 sampai 5 representasi sangat baik sampai sangat tidak baik.

Reliability adalah bahwa realisasi jasa delivery melibatkan human contact yang baik, ketepatan penghantaran, dan apakah layanan yang dijanjikan disediakan dengan benar. Indikatornya adalah: (1) Keramahan kontak personal; (2) Pelayanan purna penghantaran. Masing-masing indikator dengan derajat 1 sampai 5 representasi sangat baik sampai sangat tidak baik.

Delivery adalah penghantaran jasa sampai ke tangan konsumen secara efektif, dengan indikator konsumen puas atas jasa yang diterimanya, dengan derajat dari 1 sampai 5 representasi sangat puas sampai sangat tidak puas.

\section{HASIL DAN PEMBAHASAN}

\section{Uji Normalitas Data}

Uji normalitas data adalah uji untuk mengetahui apakah data berdistribusi normal atau tidak. Indikatornya jika L hitung < L tabel maka data berdistribusi normal, dan sebaliknya (Supranto, 2009). Hasilnya, semua L hitung lebih kecil daripada Ltabel, $(\mathrm{N}=40$ dengan $\alpha=0,05)=0,158$. Oleh karenanya dapat disimpulkan bahwa semua data pada masing-masing pengaruh adalah berasal dari populasi yang berdistribusi normal. Hal tersebut dapat dilihat pada Tabel 1 di bawah.

Tabel 1. Hasil Perhitungan Normalitas Data

\begin{tabular}{lccccl}
\hline No. & $\begin{array}{c}\text { Taksiran } \\
\text { Kesalahan }\end{array}$ & $\mathbf{N}$ & $\mathbf{L}$ hitung & $\begin{array}{r}\mathbf{L} \text { tabel } \\
\boldsymbol{\alpha}=\mathbf{0 , 0 5}\end{array}$ & Keputusan \\
\hline 1 & X terhadap Y & 40 & $-\mathbf{0 , 0 3 5 2}$ & $\mathbf{0 , 1 5 8}$ & $\begin{array}{l}\text { Berdistribusi } \\
\text { Normal } \\
\text { Berdistribusi } \\
\text { Normal }\end{array}$ \\
\hline
\end{tabular}

Sumber: Hasil Pengolahan Data 


\section{Uji Linearitas Data}

Uji linearitas data adalah uji untuk mengetahui apakah data mempunyai hubungan linier atau tidak. Indikatornya Jika F hitung $>$ F tabel $(\alpha=0,05)$ berarti data mempunyai hubungan linier, sebaliknya jika $F$ hitung $<F$ tabel $(\alpha=0,05)$ maka data tidak mempunyai hubungan linier. (Supranto, 2009). Hasil perhitungan ditunjukkan pada Tabel 2 di bawah.

Tabel 2. Hasil Uji Linearitas Data

\begin{tabular}{lllrrr}
\hline \multicolumn{2}{c}{ Hubungan } & N & ALS & F hitung & $\begin{array}{l}\text { F tabel } \\
\boldsymbol{\alpha}=\mathbf{0 , 0 5}\end{array}$ \\
\hline X terhadap Y & Koefisien & 40 & & & \\
& & & $277.1210,210$ & 17,501 & 3,03 \\
& Tuna Cocok & & 18,323 & 0,55 & 1,02 \\
Y terhadap Z & Koefisien & 40 & $327.040,740$ & 18,273 & 3,03 \\
& Tuna Cocok & & 24,425 & 0,72 & 1,02 \\
\hline
\end{tabular}

Sumber: Hasil Pengolahan Data

Keterangan: ALS adalah average least square

Hasil perhitungan di atas menunjukkan bahwa relasi X terhadap Y dan Y terhadap $\mathrm{Z}$ mempunyai koefisien signifikan karena $\mathrm{F}$ hitung $>\mathrm{F}$ tabel $(\alpha=0,05)$, dan tuna cocoknya mempunyai hubungan linear karena $F$ hitung $<\mathrm{F}$ tabel $(\alpha=0,05)$. Atas dasar hasil perhitungan ini maka nalisis selanjutnya dapat diteruskan.

\section{Uji Hipotesis}

Uji hipotesis menggunakan uji $t$, merupakan uji korelasional antar variabel secara parsial untuk mengetahui ada tidaknya hubungan dan seberapa kuat hubungannya (Supranto, 2009; Sugiono, 2012). Indikatornya jika t hitung $>\mathrm{t}$ tabel maka kedua vatiabedl berkorelasi, demikian sebaliknya. Path analysis yang baik adalah kalau model yang yang ditentukan menunjukkan bahwa korelasi variabel pertama ke variabel kedua lebih kecil daripada variabel kedua ke variabel ketiga (Latan, Temalagi, 2013).

Tabel 2. Hasil Uji Hipotesis

\begin{tabular}{|c|c|c|c|c|}
\hline No. & Hipotesis & Uji Statistik & Keputusan H0 & Kesimpulan \\
\hline 1 & $\begin{array}{l}\text { Validitas berpengaruh } \\
\text { terhadap reliabilitas }\end{array}$ & $\begin{array}{l}\mathrm{H} 0: \mathrm{V} 1 \neq 0 \\
\mathrm{H} 1: \mathrm{V} 1=0\end{array}$ & H0 ditolak & $\begin{array}{l}\text { Terkonfirmasi, karena nilai } \\
\text { t hitung }=2,054> \\
t \text { tabel }=1,050\end{array}$ \\
\hline 2 & $\begin{array}{l}\text { Reliabilitas } \\
\text { berpengaruh kualitas } \\
\text { delivery }\end{array}$ & $\begin{array}{l}\mathrm{H} 0: \mathrm{R} 1 \neq 0 \\
\mathrm{H} 1: \mathrm{R} 1=0\end{array}$ & H0 ditolak & $\begin{array}{l}\text { Terkonfirmasi, karena nilai } \\
\text { t hitung }=3,175> \\
\mathrm{t} \text { tabel }=1,050\end{array}$ \\
\hline
\end{tabular}

Sumber: Hasil Pengolahan Data

Hasil uji hipotesis ini menunjukkan bahwa kedua hipotesis terbukti dengan penolakan H0. Kemudaian model yang dibangun menunjukkan aliran stream line, karena korelasi variabel pertama ke variabel kedua lebih kecil daripada variabel kedua ke variabel ketiga benar adanya. Artinya tidak ada kesalahan berpikir dalam membangun model hubungan.

Penelitian-penelitian tentang hubungan kualitas produk dengan kepuasan konsumen telah banyak diuji, namun umumnya validitas dan reliablilitas 
dimasukkan ke dalam atribut kualitas produk, lihat misalnya Berry, Parasuraman (1991); Ha (2005); Oliver, Oliver, and Bearden (1995).

Peneltian ini mengengluarkan validitas dan reliablilitas dari atribut kualitas produk mejadi variabel predictor. Reliablilitas produk jasa berupa delivery ternyata dipengaruhi oleh barang ketika dihantarkan tepat waktu, biaya tambahan di luar tarif tidak ada, serta tidak menimbulkan klaim akibat barang rusak selama penanganan penghantaran. Semua atribut tersebut berpengaruh signifikan.

Kemudian kualitas delivery dengan atribut penghantaran barang secara efektif di tangan konsumen di-drive oleh variabel reliablilitas penghantaran dengan atribut keramahan kontak personal dari personal PT. Hanoman Sakti Pratama sebagai FF, dan juga oleh pelayanan purna penghantaran yang masih diselenggarkan ketika konsumen ada sesuatu yang masih "mengganjal" yang harus dipertanyakan. Semua atribut tersebut berpengaruh signifikan. Oleh karenanya penelitian ini mempunyai kebaruan karena memang berbeda dengan penelitian-penelitian lain sebelumnya.

\section{SIMPULAN}

Berdasarkan hasil pembahasan diperoleh kesimpulan sebagai berikut:

1. Hubungan antara validitas-reliablilitas-kualitas delivery menunjukkan aliran stream line benar adanya koefisien korelasi validitas terhadap reliablilitas lebih kecil daripada validitas terhadap kualitas delivery.

2. Reliablilitas delivery dipengaruhi oleh barang ketika dihantarkan tepat waktu, biaya tambahan di luar tarif tidak ada, serta tidak menimbulkan klaim akibat barang rusak selama penanganan penghantaran.

3. Kualitas delivery secara efektif di tangan konsumen dipengaruhi oleh reliablilitas penghantaran dengan penanganan yang ramah, serta pelayanan purna penghantaran.

\section{DAFTAR PUSTAKA}

Astriawati, N. (2016) 'Penerapan Analisis Regresi Linier Berganda Untuk Menentukan Pengaruh Pelayanan Pendidikan Terhadap Efektifitas Belajar Taruna Di Akademi Maritim Yogyakarta', Majalah Ilmiah Bahari Jogja, XIV(regresi liner), pp. 22-37.

Bernal, S.M.H., Burr, C., and Johnsen, R.E., (2002), Competitor networks: International competitiveness through collaboration-The case of small freight forwarders in the high-tech forwarder network, International Journal of Entrepreneurial Behaviour and Research, 8 (5): 239-253.

Berry, L.L., Parasuraman, A., (1991), Marketing Services - Competing through Quality, New York: the Free Press.

Brewer, A.M., (2008), The concept of value: symbolic artifact or useful tool ?, In Brewer, A.M., Button, K.J., Hensher, D.A., (2008), Handbook of Logistics and Supply-Chain Management, United Kingdom: Emerald, pp. 127- 139.

Cravens, D.W., and Piercy, N.F., (2013), Strategic Marketing, Tenth Edition. New York: McGraw-Hill. 
Christopher, M., (2011), Logistics and Supply Chain Management, HarLow: Prentice Hall.

Ha, H.Y., (2005), Effects of consumer perceptions of brand experience on the web: Brand familiarity, satisfaction and brand trust, Journal of Consumer Behaviour, 4 (6): 438-452.

Latan, H., Temalagi, S., (2013), Analisis Multivariate - Teknik dan Aplikasi Menggunakan Program IBM SPSS 20.0, Bandung: Alfabeta.

Lee, E.S., Nam, H.S., and Song, D.W., (2015), Maritime logistics and it's value defined, In Song, D.W., and Panayides, P.M., (Eds), Maritime Logistics - A Guide to Contemporary Shipping and Port Management, 2nd Edition. London: Kogan Page Limited, pp. 42-51.

Oliva, T.A., Oliva, R.L., and Bearden, W.O., (1995), The relationships among consumer satisfaction, involvement, and product performance: A catastrophe theory application, Behavioral Science, 40 (2): 104-132.

Sugiono, (2012), Metode Penelitian Kuantitatif, Kualitatif dan R \& D, Bandung: Alfabeta.

Supranto, J., (2009), Statistik Teori dan Praktek Jilid 2, Jakarta: penerbit Erlangga.

Tjiptono, F., (2012), Service Management - Mewujudkan Layanan Prima, Yogyakarta: CV. Andi Offset.

Van Raaij, W.F., and Pruyn, ATH., (1998), Customer control and evaluation of service validity and reliability, Psychology and Marketing, 15 (8): 811-832.

Wood, D.F., Barone, A.P., Murphy, P.R., Wardlow, D.L. (2002), International Logistics, Second Edition. New York: Amacom.

Undang-Undang Nomor 17 Tahun 2008 tentang Pelayaran. 